\title{
Balancing the Activity and Selectivity of Propane Oxidative Dehydrogenation on $\mathrm{NiOOH}(001)$ and (010)
}

\author{
Lisheng $\mathrm{Li}^{1} \cdot$ Hua Wang ${ }^{1} \cdot$ Jinyu Han ${ }^{1} \cdot$ Xinli Zhu ${ }^{1}$ Q Qingfeng $\mathrm{Ge}^{2}$
}

Received: 7 July 2020 / Revised: 10 July 2020 / Accepted: 11 July 2020 / Published online: 5 August 2020

(C) The Author(s) 2020

\begin{abstract}
Propane oxidative dehydrogenation (ODH) is an energy-efficient approach to produce propylene. However, ODH suffers from low propylene selectivity due to a relatively higher activation barrier for propylene formation compared with that for further oxidation. In this work, calculations based on density functional theory were performed to map out the reaction pathways of propane ODH on the surfaces (001) and (010) of nickel oxide hydroxide (NiOOH). Results show that propane is physisorbed on both surfaces and produces propylene through a two-step radical dehydrogenation process. The relatively low activation barriers of propane dehydrogenation on the $\mathrm{NiOOH}$ surfaces make the $\mathrm{NiOOH}$-based catalysts promising for propane ODH. By contrast, the weak interaction between the allylic radical and the surface leads to a high activation barrier for further propylene oxidation. These results suggest that the catalysts based on $\mathrm{NiOOH}$ can be active and selective for the ODH of propane toward propylene.
\end{abstract}

Keywords Density functional theory $\cdot$ Oxidative dehydrogenation $\cdot$ Propane $\cdot$ Nickel oxide hydroxide $\cdot$ Two-step radical mechanism $\cdot$ Selectivity

\section{Introduction}

The demand for propylene has remarkably increased over the past decade. Such increase is predicted to continue due to its importance as an industrial chemical in the production of polypropylene, propylene oxide, acrylic acid, ethanol, acrylonitrile, and other products [1-7]. Propylene can be produced from catalytic and steam cracking, as well as propane dehydrogenation (PDH) [8-10]. These processes suffer from high energy consumption because of the high endothermic reactions and fast deactivation of catalysts due to carbon deposits. In addition, catalytic and steam cracking use nonrenewable petroleum-based feedstock, making these processes unsustainable [11].

Xinli Zhu

xinlizhu@tju.edu.cn

Qingfeng Ge

qge@chem.siu.edu

1 Collaborative Innovation Centre of Chemical Science and Engineering, School of Chemical Engineering and Technology, Tianjin University, Tianjin 300072, China

2 Department of Chemistry and Biochemistry, Southern Illinois University, Carbondale, IL 62901, USA
Over the past decade, the exploitation of shale gas has provided an abundant supply of light alkanes, including propane, making PDH and oxidative dehydrogenation (ODH) potentially cost-effective processes for propylene production [11-13]. ODH has the following advantages over PDH: (1) The ODH reaction is exothermic with a reaction enthalpy of $-117 \mathrm{~kJ} / \mathrm{mol}$ and is highly favorable over the PDH reaction ( $\Delta H=124 \mathrm{~kJ} / \mathrm{mol}$ ); (2) The presence of oxidation reagents in ODH helps oxidize the residual carbon, thereby preventing coke deposition [14-16]. However, the presence of oxidation reagents in $\mathrm{ODH}$ may cause the further oxidation of propylene to either $\mathrm{CO}$ or $\mathrm{CO}_{2}$, resulting in a low yield of propylene [7, 17]. Therefore, improving the selectivity to propylene while taking advantage of the thermodynamics of ODH is important in implementing the propane ODH technology in the industrial production of propylene.

Vanadium-based catalysts have been widely studied for ODH, including the ODH of propane [15, 18-22]. Several computational studies on the catalytic performance of vanadia for propane ODH were conducted on the basis of either slab models or supported clusters [23-25]. Fu et al. [26] investigated propane ODH over the $\mathrm{V}_{2} \mathrm{O}_{5}(001)$ surface and found that the $\mathrm{C}-\mathrm{H}$ bond may be activated at either the terminal or the bridging lattice $\mathrm{O}$ atoms. They concluded 
that the $\mathrm{V}_{2} \mathrm{O}_{5}(001)$ surface is not a highly selective catalyst for the $\mathrm{ODH}$ reaction due to facile further oxidation [26]. Marin et al. [27] analyzed the ODH reaction on a vanadium monolayer supported on the $\mathrm{TiO}_{2}(001)$ surface; they concluded that $\mathrm{TiO}_{2}$ not only improves the catalytic activity of the vanadium monolayer but also increases its selectivity toward propylene by limiting further oxidation reaction. Gong et al. [28] proposed that propane ODH over $\mathrm{Al}_{2} \mathrm{O}_{3}$-supported vanadia can be divided into two steps: the initial $\mathrm{V}=\mathrm{O}$-assisted $\mathrm{ODH}$, followed by pure dehydrogenation after the surface loses its terminal $\mathrm{O}$ atom. Electronic structure analysis demonstrated that the Bader charge value and the $\mathrm{p}$-band location of the active $\mathrm{O}$ atoms affected the reactivity by modulating the activation barrier for breaking the $\mathrm{C}-\mathrm{H}$ bond $[28,29]$.

Nickel-based catalysts have also been widely used in ODH reactions. In particular, $\mathrm{NiO}$ has been shown to activate the $\mathrm{C}-\mathrm{H}$ bond of light alkanes [30-32]. Guo et al. [30] studied $\mathrm{CH}_{4}$ activation over $\mathrm{NiO}$-based catalysts by using $\mathrm{NiO} / \mathrm{ZrO}_{2}$ and $\mathrm{NiO} / \mathrm{MgAl}_{2} \mathrm{O}_{4}$ as the model catalysts and found that $\mathrm{ZrO}_{2}$ enhances the activity of $\mathrm{NiO}$ for $\mathrm{C}-\mathrm{H}$ activation by weakening the $\mathrm{Ni}-\mathrm{O}$ bonds. Liu et al. [32] studied the ODH of ethane on the $\mathrm{NiO}$ catalyst on the basis of the results of density functional theory (DFT) calculations and found that $\mathrm{NiO}(100)$ and $\mathrm{NiO}(110)$ exhibited different activities toward ethane ODH. Although the reactivities of these catalysts varied, the ability of the $\mathrm{Ni}-\mathrm{O}$ pairs to activate the $\mathrm{C}-\mathrm{H}$ bonds in the light alkanes was clearly demonstrated. Furthermore, reports have stated that the catalysts based on the $\mathrm{Ni}-\mathrm{Al}$ mixed oxides derived from the double layered hydroxides can actively break the $\mathrm{C}-\mathrm{H}$ bonds of light alkanes while exhibiting an improved selectivity of alkenes over the $\mathrm{NiO} / \mathrm{Al}_{2} \mathrm{O}_{3}$ catalysts $[33,34]$.

Nickel oxide hydroxide $(\mathrm{NiOOH})$ is a precursor to the preparation of $\mathrm{NiO}$ and has been widely investigated for oxygen evolution reactions (OERs) in electro/photocatalytic water splitting systems [35-38]. NiOOH shows high activity for water oxidation, which is rate limiting for the electrocatalytic water splitting reaction. $\mathrm{NiOOH}$-based materials are also promising electrocatalysts for rechargeable batteries. The ODH of propane on $\mathrm{NiOOH}$ may be performed under mild electrocatalysis condition owing to the electronic and structural properties of the double-layer hydroxide. The $\mathrm{Ni}-\mathrm{O}$ pairs can be exposed in a controllable manner; thus, we hypothesize that $\mathrm{NiOOH}$ may be tuned to have an optimal oxidation power for the activation of the $\mathrm{C}-\mathrm{H}$ bond of propane while preventing the further oxidation of propylene. Although $\mathrm{NiOOH}$ has not been reported as a catalyst for thermal catalysis, studies on the thermal stability of $\beta-\mathrm{Ni}(\mathrm{OH})_{2}-\beta-\mathrm{NiOOH}$ systems indicate that the decomposition of $\beta-\mathrm{Ni}(\mathrm{OH})_{2}-\beta-\mathrm{NiOOH}$ systems occurs in a fairly wide temperature range and is far from being complete even at $300{ }^{\circ} \mathrm{C}[39,40]$. In addition, the NiO-based catalyst has been shown to be active for alkane oxidation at a relatively low temperature and with the ODH of ethane at $240{ }^{\circ} \mathrm{C}$ [41]. In oxidative reactions involving alkanes, the formation of surface hydroxyls on the catalyst is anticipated. Therefore, we choose $\beta-\mathrm{NiOOH}$ as the model and believe that it has potential to be a catalyst for the ODH of propane under mild conditions.

In the present study, we map out the reaction pathways, including water formation and reoxidation of the ODH of propane on the $\beta-\mathrm{NiOOH}(001)$ and (010) surfaces. Our results indicate that $\mathrm{NiOOH}$ can be an active and selective catalyst for propane ODH. Aiming to understand the role of $\mathrm{O}$ atoms in the $\mathrm{ODH}$ reaction, we analyze the electronic structure of lattice $\mathrm{O}$ atoms on the (001) and (010) surfaces.

\section{Methodology and Computational Details}

Spin-polarized DFT calculations were performed by using the Vienna Ab initio Simulation Package code [42]. Projector-augmented wave potentials [43] with a cutoff energy of $400 \mathrm{eV}$ and the Perdew-Burke-Ernzerhof (PBE) exchange-correlation functional [44] were used in the calculations. The on-site self-interaction was corrected using the DFT $+U$ approach with a $U-\mathrm{J}$ value of $5.5 \mathrm{eV}$ [38]. The DFT-D3 method was used to account for the van der Waals dispersion interactions [45]. All the structures were relaxed until the maximum force on the movable atoms was less than $0.01 \mathrm{eV} / \AA \AA$.

The structural and electronic analyses of $\mathrm{NiOOH}$ showed two different phases, i.e., $\beta-\mathrm{NiOOH}$ and $\gamma$ - $\mathrm{NiOOH}[37$, 46-48]. In the present work, we selected the $\beta-\mathrm{NiOOH}$ phase, which has a staggered configuration of intercalated protons $[47,48]$ and constructed the active surfaces for the study of propane $\mathrm{ODH}$. The $\beta$-NiOOH (001) surface was modeled with either a one-layer or two-layer slab in a $(2 \times 4)$ surface unit cell. The atoms in the bottom layer of the twolayer slab were fixed at their corresponding bulk positions during optimization. The propane adsorption energy on the two-layer slab was shown to be similar to that on the onelayer slab. Consequently, propane ODH reaction was simulated using the one-layer slab. The $\beta-\mathrm{NiOOH}(010)$ surface was modeled with a two-layer slab in a $(1 \times 2)$ surface unit cell. A vacuum space of $15 \AA$ was inserted to build the (001) and (010) slabs. A $3 \times 3 \times 1$ grid was used for k-space sampling [49]. The supercells of the (001) and (010) models were $10.38 \times 12.19 \times 19.03 \AA^{3}$ and $9.13 \times 10.38 \times 19.57 \AA^{3}$, respectively. The top and side views of the $\mathrm{NiOOH}(001)$ and (010) surfaces are illustrated in Fig. 1.

Optimized adsorption minima were used to construct the elementary reaction steps along the reaction pathway. Transition states (TSs) were determined using the climbing image nudged elastic band (CI-NEB) algorithm and 


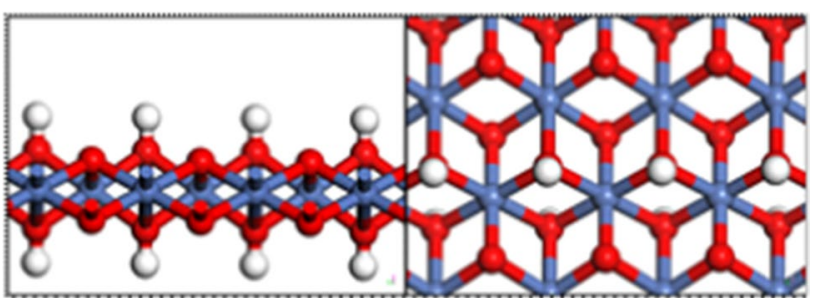

(a)

(b)

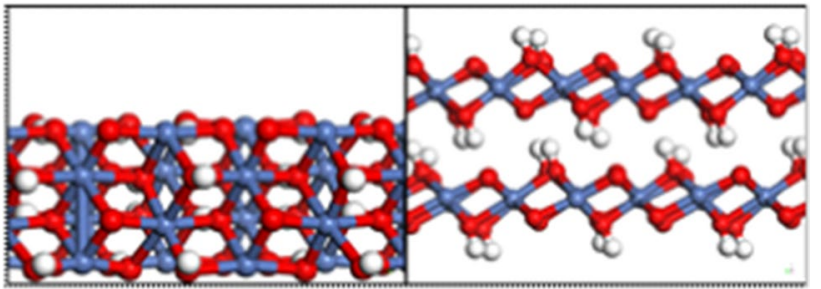

(c)

(d)

Fig. 1 Configurations of the $\mathrm{NiOOH}(001)$ and (010) surfaces: a side view of $\mathrm{NiOOH}(001)$, b top view of $\mathrm{NiOOH}(001)$, $\mathbf{c}$ side view of $\mathrm{NiOOH}(010)$, d top view of NiOOH (010). Red, blue, and white balls denote the $\mathrm{O}, \mathrm{Ni}$, and $\mathrm{H}$ atoms, respectively

the dimer method [50, 51]. A total of five images generated from the linear interpolation between the initial state (IS) and the final state (FS) were used as the initial prediction for the reaction coordinates and were optimized using the nudged elastic band algorithm. The dimer method was then used on the images close to the TS to locate the exact saddle point. The activation barrier $\left(E_{\mathrm{a}}\right)$ was determined as the energy difference between the TS and IS, and the reaction energy was calculated as the energy difference between the FS and IS. Frequency analysis was applied to all stationary points. The TSs were confirmed to have one imaginary mode corresponding to the mode for $\mathrm{C}-\mathrm{H}$ bond breaking. Zero-point energy corrections were applied to all reported energy values.

Adsorption energy $\left(E_{\text {ads }}\right)$ is defined as

$E_{\text {ads }}=E_{\text {adsorbate/surface }}-E_{\text {surface }}-E_{\text {adsorbate }}$

where $E_{\text {adsorbate/surface, }} E_{\text {surface, }}$ and $E_{\text {adsorbate }}$ represent the total energies of the slab with the adsorbate, the clean slab, and the isolated adsorbate, respectively.

\section{Results and Discussion}

\section{Thermal Stability of NiOOH}

To test whether NiOOH has sufficient thermal stability during propane $\mathrm{ODH}$ reaction, we first calculated the dehydration of surface hydroxyl groups from the $\mathrm{NiOOH}(001)$ and (010) surfaces to form water. The results are shown in Fig. 2. On the $\mathrm{NiOOH}$ (001) surface, a proton transfers from one hydroxyl group to another to form adsorbed $\mathrm{H}_{2} \mathrm{O}$ (Fig. 2a), which has a high activation barrier of $2.25 \mathrm{eV}$ and is endothermic by $1.05 \mathrm{eV}$. Subsequently, the $\mathrm{H}_{2} \mathrm{O}$ desorbs from the surface, leaving an oxygen vacancy and consuming $0.82 \mathrm{eV}$ energy. On the $\mathrm{NiOOH}(010)$ surface, the $\mathrm{H}_{2} \mathrm{O}$ formation process (Fig. 2b) is similar to that on the (001) surface. However, it has a slightly higher activation barrier $(2.51 \mathrm{eV})$ and is more endothermic $(1.58 \mathrm{eV})$ than that on $\mathrm{NiOOH}(001)$. In addition, the desorption of $\mathrm{H}_{2} \mathrm{O}$ is endothermic by $0.62 \mathrm{eV}$. Clearly, the dehydration from both $\mathrm{NiOOH}$ surfaces has high activation barriers $(2.25-2.51 \mathrm{eV})$, which are remarkably higher than those for dehydrogenation of propane

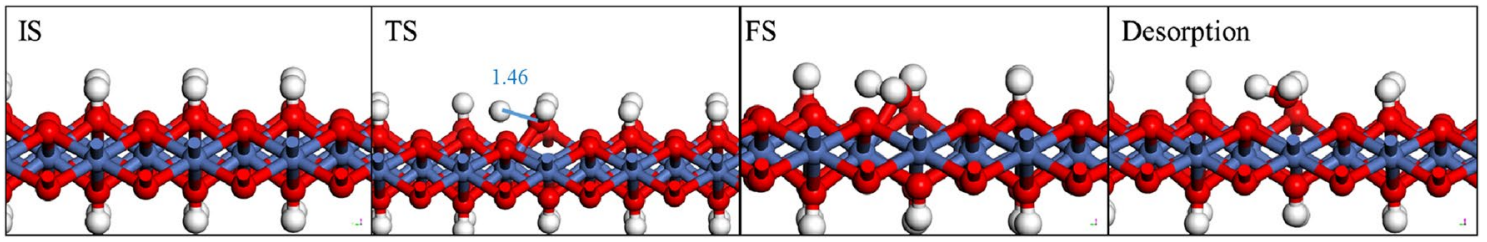

(a) $E_{\mathrm{a}}=2.25 \mathrm{eV} \Delta E=1.05 \mathrm{eV} E_{\text {des }}=0.82 \mathrm{eV}$

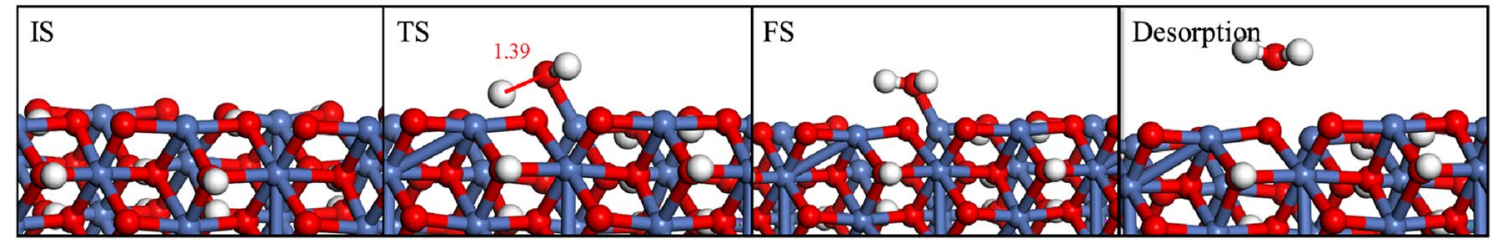

(b) $E_{\mathrm{a}}=2.51 \mathrm{eV} \Delta E=1.58 \mathrm{eV} E_{\text {des }}=0.62 \mathrm{eV}$

Fig. 2 Geometries, activation energies, and reaction energies of water formation and desorption on $\mathrm{NiOOH}(001)$ and (010) surfaces: a gasphase water formation on the (001) surface, $\mathbf{b}$ gas-phase water forma- tion on the (010) surface. Solid lines: O-H distance $(\AA)$ in TS configurations 
(0.66-1.27 eV, see below). Therefore, we expect the $\mathrm{NiOOH}$ to have sufficient thermal stability during propane $\mathrm{ODH}$.

\section{Adsorption of Propane}

To study the mechanism of propane ODH, the IS of a possible reaction pathway must be established. Figure 3 displays two possible adsorption configurations of propane on each surface: (a) and (b) on $\mathrm{NiOOH}(001)$, and (c) and (d) on $\mathrm{NiOOH}(010)$. The corresponding adsorption energies, selected interatomic distances, and Bader charges are summarized in Table 1. As shown in Table 1, $E_{\text {ads }}$ of propane on both surfaces are low, and the values on surface (001) are generally more negative than the corresponding configurations on surface (010), indicating a slightly stronger dispersive interaction on $\mathrm{NiOOH}$ (001). However, the low $E_{\text {ads }}$ values on both surfaces also indicate the physisorptive nature of propane on these surfaces; these values are consistent with the small Bader charges on the $\mathrm{O}$ and $\mathrm{H}$ atoms.

\section{Propane ODH on NiOOH (001) and (010) Surfaces}

\section{Reaction Mechanism}

Primary and secondary hydrogen atoms may be abstracted; thus, four propane ODH reaction pathways are possible on the NiOOH (001) and (010) surfaces. The activation of the $\mathrm{C}-\mathrm{H}$ bonds in alkanes may follow two mechanisms: concerted [52] and radical-mediated [23] mechanisms. The adsorption of alkane on the surface is the first step shared

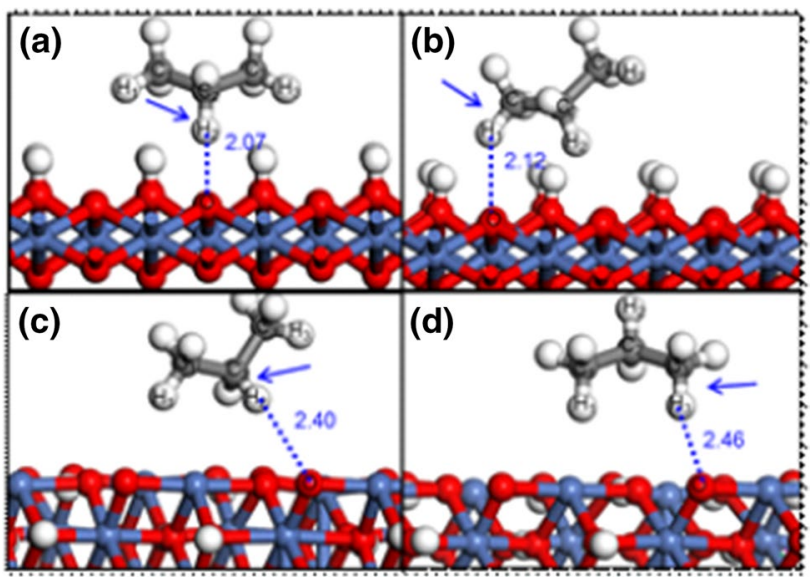

Fig. 3 Stable adsorption configurations of propane on $\mathrm{NiOOH}(001)$ and (010) surfaces. a IS of reaction pathway A of propane ODH on $\mathrm{NiOOH}(001)$; b IS of reaction pathway $\mathrm{B}$ of propane ODH on $\mathrm{NiOOH}(001)$; $\mathbf{c}$ IS of reaction pathway $\mathrm{C}$ of propane ODH on $\mathrm{NiOOH}(010)$; d IS of reaction pathway D of propane ODH on $\mathrm{NiOOH}(010)$. The arrows pointing to the bonds where the first step $\mathrm{C}-\mathrm{H}$ bonds activation occurs in pathways. Dash lines: $\mathrm{O}-\mathrm{H}$ distance $(\AA)$ in adsorption configuration
Table 1 Adsorption energies, interatomic distances, and net charges on $\mathrm{O}$ and $\mathrm{H}$ atoms in different adsorption configurations

\begin{tabular}{|c|c|c|c|c|c|}
\hline & $E_{\text {ads }}(\mathrm{eV})$ & $d_{\mathrm{C}-\mathrm{H}}(\AA)$ & $d_{\mathrm{O}-\mathrm{H}}(\AA)$ & $\mathrm{O}$ charge & $\mathrm{H}$ charge \\
\hline (a) & -0.40 & $\begin{array}{c}\mathrm{C}_{1}- \\
\mathrm{H}_{1}=1.10 \\
\mathrm{C}_{2}- \\
\mathrm{H}_{2}=1.11 \\
\mathrm{C}_{3}- \\
\mathrm{H}_{3}=1.10\end{array}$ & $\mathrm{H}_{2}-\mathrm{O}=2.07$ & -0.04 & $0.05\left(\mathrm{H}_{2}\right)$ \\
\hline (b) & -0.43 & $\begin{array}{c}\mathrm{C}_{1}- \\
\mathrm{H}_{1}=1.10 \\
\mathrm{C}_{2}- \\
\mathrm{H}_{2}=1.10 \\
\mathrm{C}_{3}- \\
\mathrm{H}_{3}=1.10\end{array}$ & $\mathrm{H}_{1}-\mathrm{O}=2.12$ & -0.05 & $0.05\left(\mathrm{H}_{1}\right)$ \\
\hline (c) & -0.13 & $\begin{aligned} \mathrm{C}_{1}- & \\
\mathrm{H}_{1} & =1.11 \\
\mathrm{C}_{2}- & \\
\mathrm{H}_{2} & =1.10 \\
\mathrm{C}_{3}- & \\
\mathrm{H}_{1} & =1.10\end{aligned}$ & $\mathrm{H}_{2}-\mathrm{O}=2.40$ & -0.10 & $0.04\left(\mathrm{H}_{2}\right)$ \\
\hline (d) & -0.19 & $\begin{aligned} \mathrm{C}_{1}- & \\
\mathrm{H}_{1} & =1.10 \\
\mathrm{C}_{2}- & \\
\mathrm{H}_{2} & =1.11 \\
\mathrm{C}_{3}- & \\
\mathrm{H}_{3} & =1.10\end{aligned}$ & $\mathrm{H}_{1}-\mathrm{O}=2.46$ & -0.08 & $0.04\left(\mathrm{H}_{1}\right)$ \\
\hline
\end{tabular}

Negative charge values indicate gaining electronic charge, whereas positive values indicate losing electron

by both mechanisms. In the concerted mechanism, the alkane molecule first dehydrogenates to form an alkyl group adsorbed on the catalyst. The concerted pathway features a four-center TS in which the Lewis base site abstracts the hydrogen atom and the nearby Lewis acid center binds the carbon atom of the alkyl. In the radical mechanism, the hydrogen atom of a $\mathrm{C}-\mathrm{H}$ bond is transferred to a surface $\mathrm{O}$ atom, forming a surface hydroxyl species. The alkyl radical may rapidly bind another surface $\mathrm{O}$ atom, resulting in a surface alkoxy species.

For propane $\mathrm{ODH}$ on $\mathrm{NiOOH}$, we could not isolate a TS for the $\mathrm{C}-\mathrm{H}$ activation following the concerted mechanism on either NiOOH (001) or (010). Based on the weak physisorptive nature and the steric hindrance of the propane molecule at the surface, we predicted that the reaction would likely follow the radical mechanism.

Following the radical mechanism, the formation of propylene from propane involves two consecutive dehydrogenation steps. The first dehydrogenation step converts propane $\left(\mathrm{C}_{3} \mathrm{H}_{8}\right)$ to a propyl radical species $\left(\mathrm{C}_{3} \mathrm{H}_{7}\right)$, and propyl radical species bind to the surface $\left(\mathrm{C}_{3} \mathrm{H}_{7}^{*}\right)$. The second dehydrogenation step transforms the surface propyl species $\left(\mathrm{C}_{3} \mathrm{H}_{7}^{*}\right)$ to propylene $\left(\mathrm{C}_{3} \mathrm{H}_{6}\right)$. Two propyl species, i.e., n-propyl $\left(\mathrm{CH}_{3} \mathrm{CH}_{2} \mathrm{CH}_{2}^{*}\right)$ and i-propyl $\left(\left(\mathrm{CH}_{3}\right)_{2} \mathrm{CH}^{*}\right)$, may form, 
depending on the order of the $\mathrm{H}$ atom being abstracted first. In the present study, gas-phase radical coupling reactions were not considered.

\section{Reaction Pathways on NiOOH (001) and (010) Surfaces}

Four possible pathways, depending on the ISs on the two surfaces, have been identified and are shown in Fig. 3. The pathway that starts by first abstracting a secondary hydrogen atom of the propane on the (001) surface is denoted as pathway A, whereas the one that starts by first abstracting a primary hydrogen atom is labeled as pathway $\mathrm{B}$. The corresponding pathways on the (010) surface are designated as pathways $\mathrm{C}$ and $\mathrm{D}$, respectively. The TSs along each pathway have been isolated and are shown in Figs. 4 and 5. The interatomic distances in the TSs are summarized in Table 2.
Along pathway A, the physisorbed propane (marked as IS-A) overcomes a barrier of $0.79 \mathrm{eV}$ to break the secondary $\mathrm{C}-\mathrm{H}$ bond and form an i-propyl radical, which is denoted as Int-A1. At TS-A1, the $\mathrm{C}-\mathrm{H}$ bond of methylene is stretched from 1.10 to $1.39 \AA$, and the distance between the abstracted $\mathrm{H}$ atom and the lattice $\mathrm{O}$ atom is reduced to $1.27 \AA$. This dehydrogenation step is slightly exothermic by $-0.03 \mathrm{eV}$. Subsequently, the i-propyl radical binds to another lattice $\mathrm{O}$ atom, forming intermediate state Int-A2 and releasing an energy of $2.59 \mathrm{eV}$. For the second dehydrogenation step, IntA2 can be activated to form propylene (denoted as Int-A3) via TS TS-A2 with $\mathrm{C}-\mathrm{H}$ and $\mathrm{O}-\mathrm{H}$ distances at $1.41 \AA$ and $1.29 \AA$, respectively. The activation barrier of the second dehydrogenation step is $0.74 \mathrm{eV}$. The second dehydrogenation step is slightly endothermic by $0.26 \mathrm{eV}$. Subsequently, the resulting propylene desorbs from the surface with an energy cost of $0.70 \mathrm{eV}$.
Fig. 4 Optimized geometries of TSs and reaction pathways of propane $\mathrm{ODH}$ on the $\mathrm{NiOOH}$ (001) surface. Pathway A: The first $\mathrm{C}-\mathrm{H}$ bond activation step occurs at the methylene group. Pathway B: The C-H bond activation step occurs at the methyl group. Black dash line: catalyst cycle. The figures show the distances of $\mathrm{O}-\mathrm{H}$ and $\mathrm{C}-\mathrm{H}(\AA)$

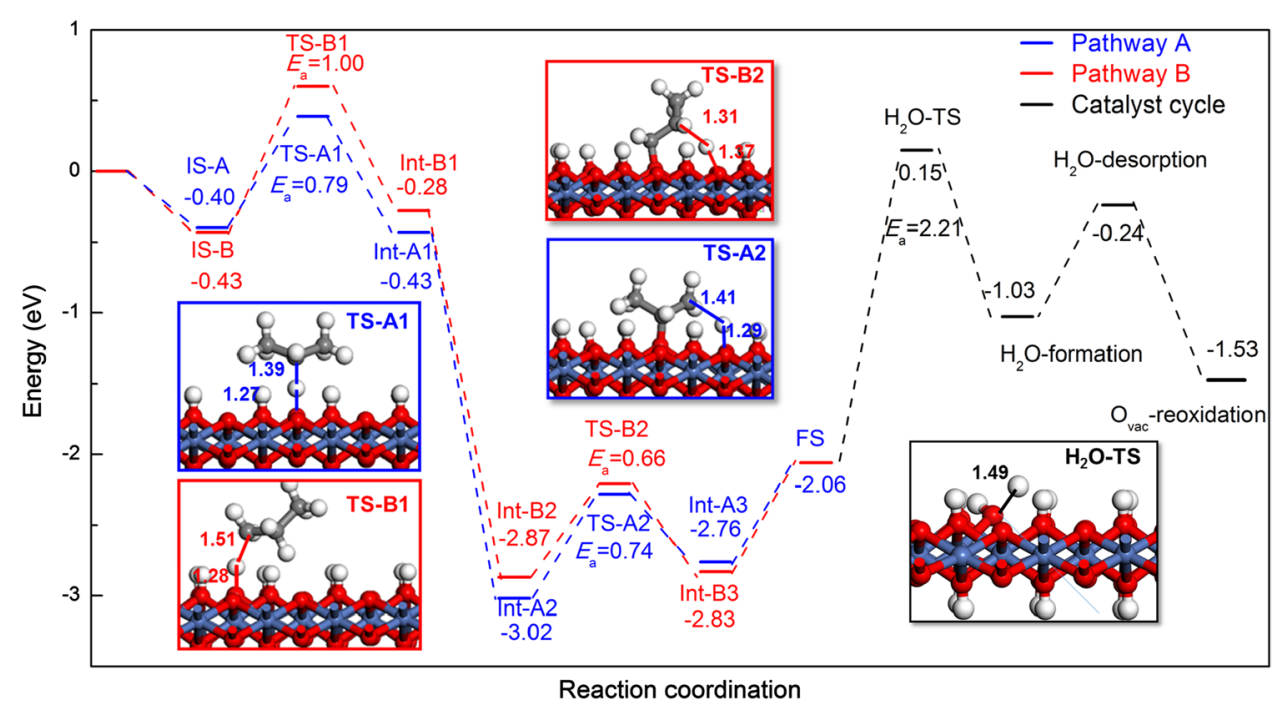

Fig. 5 Reaction pathways of propane $\mathrm{ODH}$ on the $\mathrm{NiOOH}$ (010) surface and optimized geometries of TSs. Pathway C: The first $\mathrm{C}-\mathrm{H}$ bond activation step occurs at the methylene group. Pathway D: The $\mathrm{C}-\mathrm{H}$ bond activation step occurs at the methyl group. The bond distances of $\mathrm{O}-\mathrm{H}$ and $\mathrm{C}-\mathrm{H}$ are in $\AA$

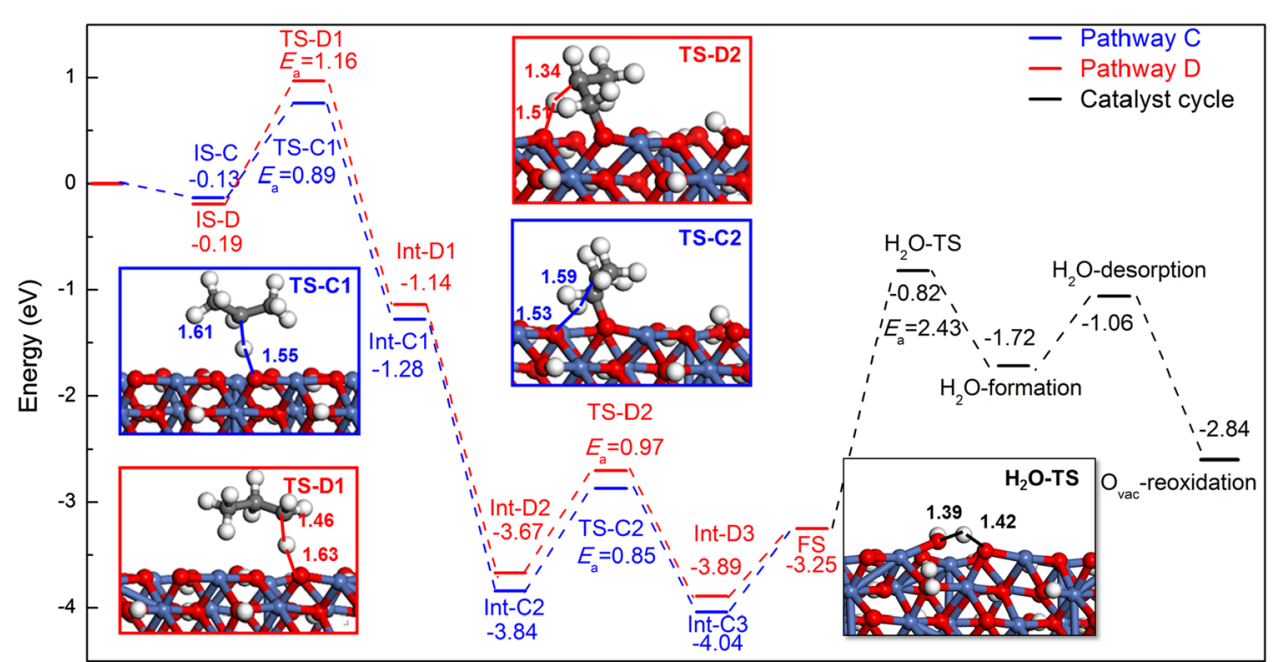

Reaction coordination 
Table 2 Activation barriers $(\mathrm{eV})$ and bond distances $(\AA)$ of the $\mathrm{C}-\mathrm{H}$ and $\mathrm{O}-\mathrm{H}$ in the TSs for the dehydrogenation steps

\begin{tabular}{llllc}
\hline Surface & Elementary step & $\begin{array}{l}\text { Activation barrier } \\
(\mathrm{eV})\end{array}$ & $d_{\mathrm{C}-\mathrm{H}}(\AA)$ & $d_{\mathrm{O}-\mathrm{H}}(\AA)$ \\
\hline$(001)$ & $\left(\mathrm{CH}_{3}\right)_{2} \mathrm{CH}_{2} \rightarrow\left(\mathrm{CH}_{3}\right)_{2} \mathrm{CH}^{*}+\mathrm{H}^{*}$ & 0.79 & 1.39 & 1.27 \\
& $\left(\mathrm{CH}_{3}\right)_{2} \mathrm{CH}^{*} \rightarrow \mathrm{CH}_{3} \mathrm{CHCH}_{2}^{*}+\mathrm{H}^{*}$ & 0.74 & 1.41 & 1.29 \\
& $\left(\mathrm{CH}_{3}\right)_{2} \mathrm{CH}_{2} \rightarrow \mathrm{CH}_{3} \mathrm{CH}_{2} \mathrm{CH}_{2}^{*}+\mathrm{H}^{*}$ & 1.00 & 1.51 & 1.28 \\
& $\mathrm{CH}_{3} \mathrm{CH}_{2} \mathrm{CH}_{2}^{*} \rightarrow \mathrm{CH}_{3} \mathrm{CHCH}_{2}^{*}+\mathrm{H}^{*}$ & 0.66 & 1.31 & 1.37 \\
$(010)$ & $\left(\mathrm{CH}_{3}\right)_{2} \mathrm{CH}_{2} \rightarrow\left(\mathrm{CH}_{3}\right)_{2} \mathrm{CH}^{*}+\mathrm{H}^{*}$ & 0.89 & 1.61 & 1.55 \\
& $\left(\mathrm{CH}_{3}\right)_{2} \mathrm{CH}^{*} \rightarrow \mathrm{CH}_{3} \mathrm{CHCH}_{2}^{*}+\mathrm{H}^{*}$ & 0.85 & 1.59 & 1.53 \\
& $\left(\mathrm{CH}_{3}\right)_{2} \mathrm{CH}_{2} \rightarrow \mathrm{CH}_{3} \mathrm{CH}_{2} \mathrm{CH}_{2}^{*}+\mathrm{H}^{*}$ & 1.16 & 1.46 & 1.63 \\
& $\mathrm{CH}_{3} \mathrm{CH}_{2} \mathrm{CH}_{2}^{*} \rightarrow \mathrm{CH}_{3} \mathrm{CHCH}_{2}^{*}+\mathrm{H}^{*}$ & 0.97 & 1.34 & 1.51 \\
\hline
\end{tabular}

Following pathway $\mathrm{B}$, the activation barrier of the first dehydrogenation step of activating the $\mathrm{C}-\mathrm{H}$ bond of the methyl group is $1.00 \mathrm{eV}$, which is significantly higher than that of pathway A. The breaking of the second $\mathrm{C}-\mathrm{H}$ bond has an activation barrier of $0.66 \mathrm{eV}$, which is lower than that in pathway A. The desorption of propylene is endothermic by $0.77 \mathrm{eV}$.

For propylene production on the (001) surface, the activation barriers of the first dehydrogenation step are higher than those of the other steps along pathways A and B; moreover, the difference is more evident in pathway $\mathrm{B}$. To complete the catalytic cycle, two hydroxyl groups formed through propane dehydrogenation may disproportionate to form $\mathrm{H}_{2} \mathrm{O}$ that has an activation barrier of $2.21 \mathrm{eV}$ and is endothermic by $1.03 \mathrm{eV}$. Then, the formed $\mathrm{H}_{2} \mathrm{O}$ desorbs from the catalyst surface, consuming an energy of $0.79 \mathrm{eV}$ and leaving an oxygen vacancy behind. The overall $\mathrm{H}_{2} \mathrm{O}$ formation and desorption process are highly endothermic, consuming an energy of $1.82 \mathrm{eV}$ on the (001) surface. The reoxidation of the surface by gas-phase $\mathrm{O}_{2}$ is exothermic, releasing an energy of $1.29 \mathrm{eV}$. The reoxidation of the vacancy $\mathrm{O}$ sites is facile in the presence of $\mathrm{O}$ and not likely relevant with kinetics in reaction $[53,54]$. The activation barrier of $\mathrm{H}_{2} \mathrm{O}$ formation from the $\mathrm{ODH}$-formed $-\mathrm{OH}$ is similar to that from the original $-\mathrm{OH}$ on the clean $\mathrm{NiOOH}(001)$ surface and is much higher than that of dehydrogenation of propane. This comparison indicates that the dehydration step is likely the rate-determining step of the overall reaction, and the surface is stable during the reaction of propane $\mathrm{ODH}$.

On the $\mathrm{NiOOH}(010)$ surface, the first dehydrogenation (IS-C) step following pathway $\mathrm{C}$ breaks the $\mathrm{C}-\mathrm{H}$ bond of the methylene group to produce an i-propyl radical, whereas the hydrogen atom adsorbs on the lattice $\mathrm{O}$ atom. The resulting structure is denoted as Int-C1. This step overcomes an activation barrier of $0.89 \mathrm{eV}$ and is exothermic by $-1.15 \mathrm{eV}$. At the TS (denoted as TS-C1), the $\mathrm{C}-\mathrm{H}$ bond is elongated from 1.10 to $1.61 \AA$, and the $\mathrm{O}-\mathrm{H}$ distance decreases to $1.55 \AA$. Similar to pathway $\mathrm{A}$, the resulting i-propyl radical binds to another lattice $\mathrm{O}$ atom to form intermediate Int-C2, releasing an energy of $2.56 \mathrm{eV}$ as a result of strong adsorption. The dehydrogenation of Int- $\mathrm{C} 2$ proceeds by elongating the $\mathrm{C}-\mathrm{H}$ bond of the methyl group from 1.14 to $1.59 \AA$ at TS-C2. This step has an activation barrier of $0.85 \mathrm{eV}$ and is slightly exothermic by $-0.20 \mathrm{eV}$. Meanwhile, the activation barriers of the two consecutive dehydrogenation steps are 1.16 and $0.97 \mathrm{eV}$ along pathway D. Both steps must overcome higher activation barriers than the corresponding steps of pathway $\mathrm{C}$.

Along pathways $\mathrm{C}$ and $\mathrm{D}$, the desorption of propylene is endothermic by 0.79 and $0.64 \mathrm{eV}$, respectively. The dehydration from two ODH-formed hydroxyl groups that form $\mathrm{H}_{2} \mathrm{O}$ has an activation barrier of $2.43 \mathrm{eV}$ and is endothermic by $1.53 \mathrm{eV}$. Then, the desorption of $\mathrm{H}_{2} \mathrm{O}$ with the formation of an oxygen vacancy consumes an energy of $0.66 \mathrm{eV}$. The overall $\mathrm{H}_{2} \mathrm{O}$ formation and desorption on the (010) surface consumes an energy of $2.19 \mathrm{eV}$. The filling of the oxygen vacancy $\mathrm{O}$ on the (010) surface is strongly exothermic by $-1.78 \mathrm{eV}$. On the (010) surface, propane dehydrogenation process is also more feasible than water formation.

The comparison of the pathways on the (001) surface (A and $B$ ) with those on the $(010)$ surface $(C$ and $D)$ reveals that the (001) surface has lower activation barriers of dehydrogenation compared with (010) surface. Moreover, the water formation and desorption process on (001) surface are less endothermic than that on (010) surface. These results indicate that (001) surface is more kinetically feasible for propane $\mathrm{ODH}$ and thermodynamically favorable for $\mathrm{H}_{2} \mathrm{O}$ formation process compared with the (010) surface. This result can be intuitively rationalized by examining the structures of the two surfaces: the (010) surface exposes more unsaturated $\mathrm{O}$ atoms, making it more oxidative than the (001) surface. Furthermore, the $\mathrm{C}-\mathrm{H}$ bond of $\beta-\mathrm{C}$, i.e., the $\mathrm{C}$ atom of the methylene group, is more facile to break compared with the $\mathrm{C}-\mathrm{H}$ bonds of $\alpha-\mathrm{C}$. This observation is consistent with previous reports showing that the dissociation energy of the $\mathrm{C}-\mathrm{H}$ bonds of the methyl group $(420 \mathrm{~kJ} / \mathrm{mol})$ is higher than that of the methylene group $(401 \mathrm{~kJ} / \mathrm{mol})[25,55]$.

On the vanadia-based ODH catalysts, the activation barriers of dehydrogenation depend on the nature and oxidation state of vanadium $[28,56,57]$. For example, the activation 
barriers of the first hydrogen abstraction on the monomeric and dimeric vanadium oxide supported on $\mathrm{TiO}_{2}$ are 1.73 and $1.91 \mathrm{eV}$, respectively [57]. The activation barrier for breaking the first $\mathrm{C}-\mathrm{H}$ bond of propane on an isolated silicasupported vanadium oxide site is $1.48 \mathrm{eV}$, whereas that for breaking the next $\mathrm{C}-\mathrm{H}$ bond to form propylene increases to $1.92 \mathrm{eV}$ [56]. The activation barriers we calculated are lower than those reported in the studies above, suggesting that lattice $\mathrm{O}$ atoms on $\mathrm{NiOOH}$ exhibit promising catalytic activity toward propane ODH. By contrast, the disproportion of hydroxyl groups to form $\mathrm{H}_{2} \mathrm{O}$ is energetically more favorable on $\mathrm{VO}_{x}$ than on $\mathrm{NiOOH}$ because the most common active site on vanadium oxide-based catalysts is the vanadyl oxygen site. For example, the energy cost to produce gasphase $\mathrm{H}_{2} \mathrm{O}$ is only $1.27 \mathrm{eV}$ on a monomer $\mathrm{VO}_{x} / \mathrm{TiO}_{2}$ [24].

To the best of our knowledge, a detailed DFT study of propane $\mathrm{ODH}$ on the $\mathrm{NiO}$ surface has not been reported. Lemonidou et al. [58] experimentally investigated the reaction mechanisms of ODH of ethane on Ni oxide-based catalysts and reported an activation energy of $0.95 \mathrm{eV}$ at $330^{\circ} \mathrm{C}$. Based on the DFT results, the activation barriers for breaking the $\mathrm{C}-\mathrm{H}$ bonds of ethane on the $\mathrm{Co}_{3} \mathrm{O}_{4}(111)$ surface are 1.02 and $0.87 \mathrm{eV}$ [59]. Water formation from the two hydroxyls has the largest activation barrier $(2.02 \mathrm{eV})$ and is the overall rate-determining step. Meanwhile, the activation barrier of propane $\mathrm{ODH}$ on $\mathrm{Co}_{3} \mathrm{O}_{4}(111)$ is $0.95 \mathrm{eV}$ [60]. Compared with the literature results, the activation barriers of $0.66-1.16 \mathrm{eV}$ for propane dehydrogenation on the $\mathrm{NiOOH}$ (001) and (010) surfaces are moderate, making $\mathrm{NiOOH}$ a good potential catalyst for propane $\mathrm{ODH}$.

\section{Selectivity of Propylene}

The further oxidation of the dehydrogenation intermediates is the main reason for low propylene yield in propane ODH.
We have demonstrated that the $\mathrm{NiOOH}$ surfaces exhibit a reasonable activity for the first two steps of propane dehydrogenation. We also studied the further oxidation of propylene on the (001) and (010) surfaces (Fig. 6). Based on the adsorption structures of propylene from propane dehydrogenation, we mapped out the pathways for its further oxidation. Given that the surface oxygen sites next to the adsorbed propylene are now occupied by the $\mathrm{H}$ atoms, the further oxidation of propylene at these sites is not expected to occur. Consequently, the further oxidation of propylene is likely to happen at different sites of the surface through readsorption. Propylene oxidation is commonly considered to follow two pathways: (1) activation of the double bond by the lattice $\mathrm{O}$ atoms, resulting in the formation of propylene-oxy intermediate, which is believed to be a precursor of forming propylene epoxide; and (2) activation of the $\mathrm{C}-\mathrm{H}$ bond of the terminal $\mathrm{CH}_{3}$ group, resulting in an allyl radical and the hydroxyl group on the surface, with the radical considered to be a precursor for complete combustion. Similar to propane adsorption, propylene is physisorbed on the (001) and (010) surfaces. The physisorptive nature of propylene on the surfaces allows for further oxidation to follow the second mechanism, i.e., oxidation is initiated at the methyl group. The activation barriers for breaking the $\mathrm{C}-\mathrm{H}$ bond of the methyl group on the (001) and (010) surfaces were calculated to be 1.14 and $1.27 \mathrm{eV}$ and are exothermic by -0.12 and $-0.51 \mathrm{eV}$, respectively. Interestingly, these activation barriers are higher than those of breaking the $\mathrm{C}-\mathrm{H}$ bonds in the initial propane. Consequently, propylene formation is anticipated to be favorable over further oxidation.

On the basis of the Brønsted-Evans-Polanyi (BEP) relationship [61, 62], the activation barriers for the breaking of the $\mathrm{C}-\mathrm{H}$ bond are linearly correlated with the bond dissociation energy (BDE) in the parent organic molecule and the association energy of $\mathrm{H}$ atom (HAE) to lattice $\mathrm{O}$. By
Fig. 6 Reaction pathways of propylene oxidation on the $\mathrm{NiOOH} \mathbf{a}(001)$ and $\mathbf{b}(010)$ surfaces. The overall reaction energy and activation barrier are shown for each pathway. The red lines denote the distances ( $\AA$ ) of $\mathrm{O}-\mathrm{H}$ and $\mathrm{C}-\mathrm{H}$

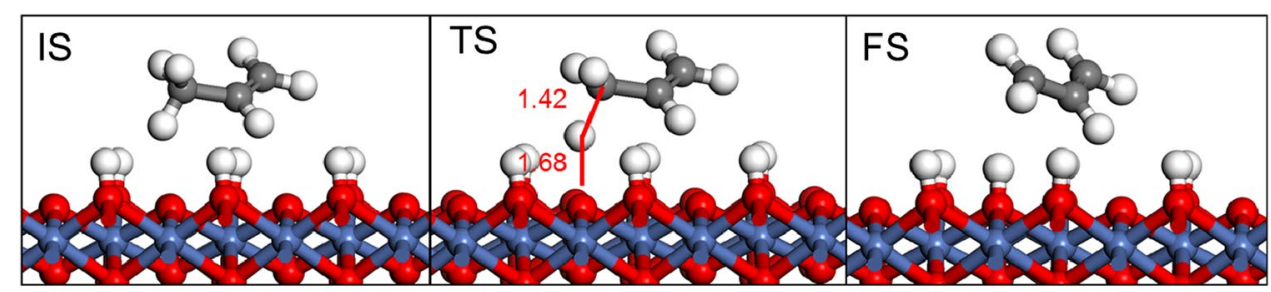

(a) $\Delta E=-0.12 \mathrm{eV} E_{\mathrm{a}}=1.14 \mathrm{eV}$

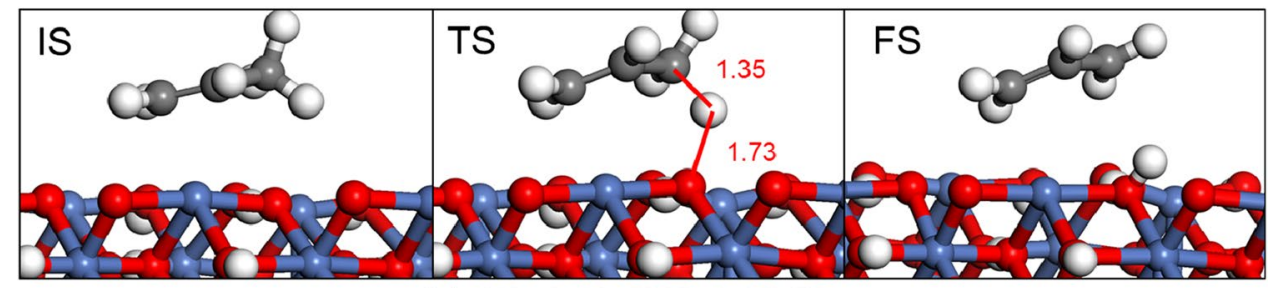

(b) $\Delta E=-0.51 \mathrm{eV} E_{\mathrm{a}}=1.27 \mathrm{eV}$ 
contrast, the BEP relationship constructed on the basis of $\mathrm{BDE}$ and HAE neglects the contribution of the interaction between the catalyst and the organic moiety to the activation barrier in the TS [63]. This BEP relationship predicts a lower activation barrier for the activation of weaker allylic $\mathrm{C}-\mathrm{H}$ bond in propylene compared with the activation of strong $\mathrm{C}-\mathrm{H}$ bonds in propane; this prediction is not consistent with the present results. Thus, the interaction between organic radical and hydroxylated surface oxygen at the TS must be considered [63]. The i-propyl and n-propyl radicals exhibit a highly localized electron density at the $\mathrm{C}$ atom on which the $\mathrm{C}-\mathrm{H}$ bond activation occurs. By contrast, as a result of propylene dehydrogenation, the allylic organic radical has an unpaired electron, which becomes delocalized. The delocalization of the unpaired electron weakens the interaction of the allylic radical, consequently destabilizing the TS. Thus, the activation barrier for the activation of the weak allylic $\mathrm{C}-\mathrm{H}$ bond in propylene is higher than the BEP relationship prediction that only considered BDE and HAE [63]. In addition, the distances of $\mathrm{O}-\mathrm{H}$ and $\mathrm{C}-\mathrm{H}$ in TSs (Fig. 6) show that the TS for breaking the allylic $\mathrm{C}-\mathrm{H}$ bond $(\mathrm{C}-\mathrm{H}$ bond in $\mathrm{CH}_{3}$ group) of propylene occurs earlier along the reaction coordinate compared with those for the formation of propylene by dehydrogenation (Figs. 4, 5) and therefore has weaker radical-surface interactions at TS $[64,65]$. Based on these analyses, we predict that the NiOOH-based propane ODH catalysts will result in high selectivity and high propylene yield.

$\mathrm{NiOOH}$ has been shown as a catalyst for OERs $[36,37$, 66], and the exposed surface $O$ sites play a vital role for its OER activity [49]. In the present work, we showed that the $\mathrm{O}$ sites on the $\mathrm{NiOOH}$ surface can activate the $\mathrm{C}-\mathrm{H}$ bonds of propane. Compared with the other ODH catalysts, the NiOOH-based catalysts exhibit comparatively low activation barriers for propane dehydrogenation. Moreover, intermediate configurations indicate that the further oxidation of adsorbed propylene is effectively inhibited on $\mathrm{NiOOH}$ due to the formation of the surface hydroxyl groups, making $\mathrm{NiOOH}$ a selective propane $\mathrm{ODH}$ catalyst with balanced activity and selectivity.

\section{Electronic Origin of the Activity for ODH}

\section{Bader Charge Analysis}

The breaking of the $\mathrm{C}-\mathrm{H}$ bonds involves electron transfer from the $\mathrm{H}$ atom to the lattice $\mathrm{O}$ atom; thus, the electronic property of the lattice $\mathrm{O}$ atom is expected to have a significant effect on ODH activity. To understand the electronic origin of the activity of the $\mathrm{NiOOH}(001)$ and (010) surfaces for activating the $\mathrm{C}-\mathrm{H}$ bond, we analyzed the electronic structures of the surface. Following the activation of the $\mathrm{C}-\mathrm{H}$ bond, the s electron of the $\mathrm{H}$ atom is partially transferred to the $\mathrm{p}$ orbitals of the lattice $\mathrm{O}$ atom. The Bader charge analysis shows that the lattice $\mathrm{O}$ atom becomes more negative after binding the $\mathrm{H}$ atom. In addition, the electronic affinity of the lattice $\mathrm{O}$ atom is positively correlated with dehydrogenation activity.

As shown in Table 3, the activation barrier of the first dehydrogenation step from the secondary $\mathrm{C}-\mathrm{H}$ bond of propane is directly proportional to the net charge on the lattice $\mathrm{O}$ atom, i.e., the higher the charge on the $\mathrm{O}$ atom, the higher the activation barrier. The difference of Bader charges of the lattice $\mathrm{O}$ atoms is also closely related to the $\mathrm{Ni}-\mathrm{O}$ bond lengths on the $\mathrm{NiOOH}(001)$ and (010) surfaces. The Ni-O bonds on the (001) and (010) surfaces are 1.96 and $1.90 \AA$, respectively. A short $\mathrm{Ni}-\mathrm{O}$ bond distance on the (010) surface corresponds to the lattice $\mathrm{O}$ atoms gaining additional electrons from the $\mathrm{Ni}$ atom while reducing its ability of abstracting $\mathrm{H}$. Consequently, the $\mathrm{NiOOH}$ (010) surface exhibits a lower dehydrogenation activity compared with the (001) surface.

\section{Density of States Analysis}

To understand the different activities of the (001) and (010) surfaces further, we analyzed the density of states (DOSs). Figure 7 shows the projected $\mathrm{p}$ DOSs of the $\mathrm{O}$ atom involved in the $\mathrm{C}-\mathrm{H}$ bond activation and $\mathrm{d}$ DOSs of $\mathrm{Ni}$ atoms next to the $\mathrm{O}$ atom. As shown in the projected DOSs, the p-derived features dominate in the energy range close to the Fermi level. As an indicator of Pauli repulsion, the relative position of the $\mathrm{p}$ states of the $\mathrm{O}$ atom to the Fermi level was used to predict the activity for $\mathrm{C}-\mathrm{H}$ bond activation. The closer the edge of the $\mathrm{p}$ states to the Fermi level, the more active the $\mathrm{O}$ atom becomes to break the $\mathrm{C}-\mathrm{H}$ bond $[28,29]$. As shown in Fig. 7a, the p states of the $\mathrm{O}$ atom on the $\mathrm{NiOOH}(001)$ surface (blue line) is closer to the Fermi level compared with the $\mathrm{O}$ atom on the $\mathrm{NiOOH}(010)$ surface. This order of the $\mathrm{p}$ states is consistent with the activity order of these surfaces to break the $\mathrm{C}-\mathrm{H}$ bonds.

Table 3 Net Bader charge of the lattice $\mathrm{O}$ atom and the activation barrier of the first dehydrogenation step from the secondary $\mathrm{C}-\mathrm{H}$ bond on different surfaces from propane

\begin{tabular}{lll}
\hline Surface & Net Bader charge of O & Activation barrier $(\mathrm{eV})$ \\
\hline $\mathrm{NiOOH}(001)$ & -0.79 & 0.79 \\
$\mathrm{NiOOH}(010)$ & -0.89 & 0.89 \\
\hline
\end{tabular}




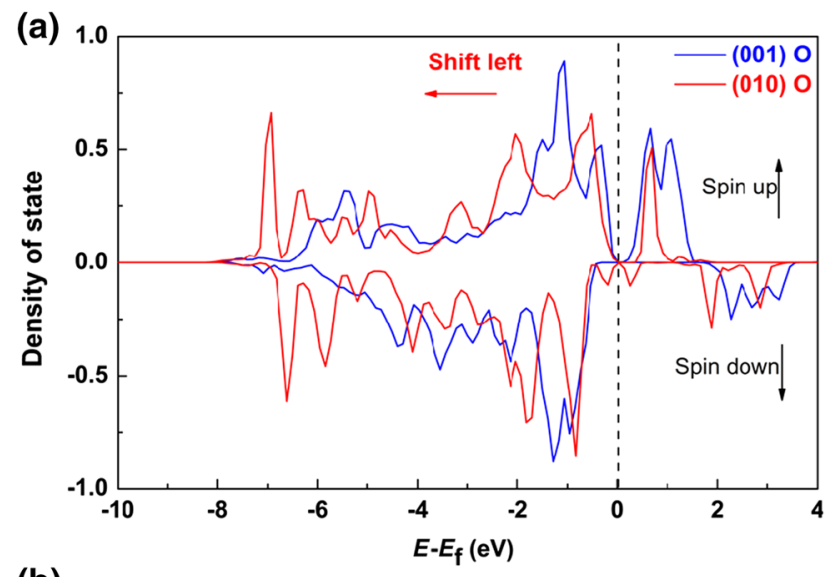

(b)

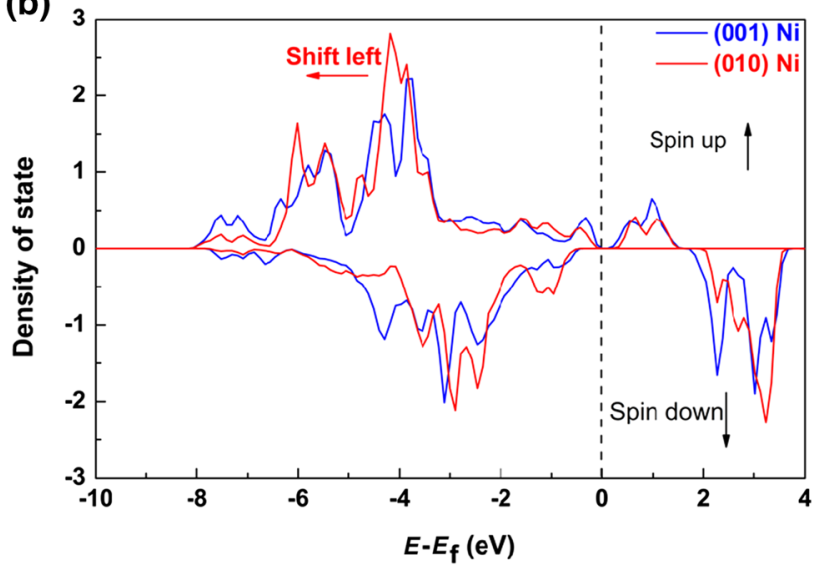

Fig. 7 a p DOSs of lattice $\mathrm{O}$ atoms; $\mathbf{b}$ d DOSs of Ni atoms

\section{Conclusions}

In this work, we report a DFT computational study of selective propane ODH to propylene on the $\mathrm{NiOOH}(001)$ and (010) surfaces. Our results show that propane and propylene are physisorbed on the $\mathrm{NiOOH}(001)$ and (010) surfaces. Four possible reaction pathways for propane ODH on the $\mathrm{NiOOH}(001)$ and (010) surfaces (i.e., two on each surface) are identified and examined. The reaction follows a radical mechanism in which the activation barriers for breaking the $\mathrm{C}-\mathrm{H}$ bonds are moderate. The hydroxyl groups formed in the dehydrogenation steps of forming propylene on the $\mathrm{NiOOH}$ (001) and (010) surfaces limit the accessibility to active $\mathrm{O}$ atoms and become disproportionate in the form of $\mathrm{H}_{2} \mathrm{O}$. The relatively weak interaction between the allylic radical and catalyst surface destabilizes the TSs due to the delocalization of unpaired electrons, resulting in a higher activation barrier for propylene dehydrogenation compared with that for propane dehydrogenation. These results demonstrate that $\mathrm{NiOOH}$ is a promising catalyst for propane ODH with improved activity and selectivity over the vanadia-based ODH catalyst. The $\mathrm{C}-\mathrm{H}$ bond activation barriers correlate with the net charge on the active lattice $\mathrm{O}$ atoms. These understandings are beneficial for the design of highly active and selective catalysts for the ODH of propane and other alkanes.

Acknowledgements We gratefully acknowledge the financial support from the National Natural Science Foundation of China (Nos. 21873067 and 21576204).

Open Access This article is licensed under a Creative Commons Attribution 4.0 International License, which permits use, sharing, adaptation, distribution and reproduction in any medium or format, as long as you give appropriate credit to the original author(s) and the source, provide a link to the Creative Commons licence, and indicate if changes were made. The images or other third party material in this article are included in the article's Creative Commons licence, unless indicated otherwise in a credit line to the material. If material is not included in the article's Creative Commons licence and your intended use is not permitted by statutory regulation or exceeds the permitted use, you will need to obtain permission directly from the copyright holder. To view a copy of this licence, visit http://creativecommons.org/licenses/by/4.0/.

\section{References}

1. Zheng B, Hua WM, Yue YH et al (2005) Dehydrogenation of propane to propene over different polymorphs of gallium oxide. $\mathrm{J}$ Catal 232(1):143-151

2. Akah A, Al-Ghrami M (2015) Maximizing propylene production via FCC technology. Appl Petrochem Res 5(4):377-392

3. Kung HH (1994) Oxidative dehydrogenation of light $\left(\mathrm{C}_{2}\right.$ to $\left.\mathrm{C}_{4}\right)$ alkanes. Adv Catal 40:1-38

4. Baek J, Yun HJ, Yun D et al (2012) Preparation of highly dispersed chromium oxide catalysts supported on mesoporous silica for the oxidative dehydrogenation of propane using $\mathrm{CO}_{2}$ : insight into the nature of catalytically active chromium sites. ACS Catal 2(9):1893-1903

5. Chen M, Xu J, Liu YM et al (2010) Supported indium oxide as novel efficient catalysts for dehydrogenation of propane with carbon dioxide. Appl Catal A Gen 377(1-2):35-41

6. Derouane EG, Parmon V, Lemos F et al (2005) Sustainable strategies for the upgrading of natural gas: fundamentals, challenges, and opportunities. Springer, Dordrecht

7. Mashayekhi NA, Kung MC, Kung HH (2014) Selective oxidation of hydrocarbons on supported Au catalysts. Catal Today 238:74-79

8. Cavani F, Ballarini N, Cericola A (2007) Oxidative dehydrogenation of ethane and propane: how far from commercial implementation? Catal Today 127(1-4):113-131

9. Liu HG, Dong XM, Xia JP et al (2019) Preparation of $\gamma-\mathrm{Al}_{2} \mathrm{O}_{3}$ via hydrothermal synthesis using $\rho-\mathrm{Al}_{2} \mathrm{O}_{3}$ as raw material for propane dehydrogenation. Trans Tianjin Univ. https://doi.org/10.1007/ s12209-019-00225-8

10. Li YX, Li JX, Yang X et al (2019) Preparation of $\mathrm{CeO}_{2}$-modified $\mathrm{Mg}(\mathrm{Al}) \mathrm{O}$-supported $\mathrm{Pt}-\mathrm{Cu}$ alloy catalysts derived from hydrotalcite-like precursors and their catalytic behavior for direct dehydrogenation of propane. Trans Tianjin Univ 25(2):169-184

11. Sattler JJHB, Ruiz-Martinez J, Santillan-Jimenez E et al (2014) Catalytic dehydrogenation of light alkanes on metals and metal oxides. Chem Rev 114(20):10613-10653

12. Li ZY, Peters AW, Platero-Prats AE et al (2017) Fine-tuning the activity of metal-organic framework-supported cobalt catalysts 
for the oxidative dehydrogenation of propane. J Am Chem Soc 139(42): 15251-15258

13. Grabowski R (2006) Kinetics of oxidative dehydrogenation of C2-C3 alkanes on oxide catalysts. Catal Rev 48(2):199-268

14. Kristoffersen HH, Neilson HL, Buratto SK et al (2017) Stability of $\mathrm{V}_{2} \mathrm{O}_{5}$ supported on titania in the presence of water, bulk oxygen vacancies, and adsorbed oxygen atoms. J Phys Chem C 121(15):8444-8451

15. Carrero CA, Schloegl R, Wachs IE et al (2014) Critical literature review of the kinetics for the oxidative dehydrogenation of propane over well-defined supported vanadium oxide catalysts. ACS Catal 4(10):3357-3380

16. Chen KD, Khodakov A, Yang J et al (1999) Isotopic tracer and kinetic studies of oxidative dehydrogenation pathways on vanadium oxide catalysts. J Catal 186(2):325-333

17. Khodakov A, Yang J, Su S et al (1998) Structure and properties of vanadium oxide-zirconia catalysts for propane oxidative dehydrogenation. J Catal 177(2):343-351

18. Delgado D, Sanchís R, Cecilia JA et al (2019) Support effects on NiO-based catalysts for the oxidative dehydrogenation (ODH) of ethane. Catal Today 333:10-16

19. Park JL, Canizales KA, Argyle MD et al (2020) The effects of doping alumina with silica in alumina-supported $\mathrm{NiO}$ catalysts for oxidative dehydrogenation of ethane. Microporous Mesoporous Mater 293:109799

20. Khodakov A, Olthof B, Bell AT et al (1999) Structure and catalytic properties of supported vanadium oxides: support effects on oxidative dehydrogenation reactions. J Catal 181(2):205-216

21. Zhang SH, Liu HC (2019) Oxidative dehydrogenation of propane over $\mathrm{Mg}-\mathrm{V}-\mathrm{O}$ oxides supported on $\mathrm{MgO}$-coated silica: structural evolution and catalytic consequence. Appl Catal A Gen 573:41-48

22. Zhang SH, Liu HC (2018) Insights into the structural requirements for oxidative dehydrogenation of propane on crystalline $\mathrm{Mg}-\mathrm{V}-\mathrm{O}$ catalysts. Appl Catal A Gen 568:1-10

23. Avdeev VI, Bedilo AF (2016) Molecular mechanism of propane oxidative dehydrogenation on surface oxygen radical sites of $\mathrm{VO}_{x} /$ $\mathrm{TiO}_{2}$ catalysts. Res Chem Intermed 42(6):5237-5252

24. Du YJ, Li ZH, Fan KN (2013) A theoretical investigation on the influence of anatase support and vanadia dispersion on the oxidative dehydrogenation of propane to propene. J Mol Catal A Chem 379:122-138

25. Huang C, Wang ZQ, Gong XQ (2018) Activity and selectivity of propane oxidative dehydrogenation over $\mathrm{VO}_{3} / \mathrm{CeO}_{2}(111)$ catalysts: a density functional theory study. Chin J Catal 39(9):1520-1526

26. Fu H, Liu ZP, Li ZH et al (2006) Periodic density functional theory study of propane oxidative dehydrogenation over $\mathrm{V}_{2} \mathrm{O}_{5}(001)$ surface. J Am Chem Soc 128(34):11114-11123

27. Alexopoulos K, Reyniers MF, Marin GB (2012) Reaction path analysis of propane selective oxidation over $\mathrm{V}_{2} \mathrm{O}_{5}$ and $\mathrm{V}_{2} \mathrm{O}_{5} / \mathrm{TiO}_{2}$. J Catal 289:127-139

28. Xiong CY, Chen S, Yang PP et al (2019) Structure-performance relationships for propane dehydrogenation over aluminum supported vanadium oxide. ACS Catal 9(7):5816-5827

29. Song YY, Wang GC (2016) A DFT study and microkinetic simulation of propylene partial oxidation on $\mathrm{CuO}(111)$ and $\mathrm{CuO}(100)$ surfaces. J Phys Chem C 120(48):27430-27442

30. Feng YC, Wang NN, Guo X (2018) Influence mechanism of supports on the reactivity of Ni-based oxygen carriers for chemical looping reforming: a DFT study. Fuel 229:88-94

31. Fan XQ, Liu DD, Zhao $\mathrm{Z}$ et al (2020) Influence of Ni/Mo ratio on the structure-performance of ordered mesoporous Ni-Mo-O catalysts for oxidative dehydrogenation of propane. Catal Today 339:67-78

32. Yu TT, Li Z, Zheng HL et al (2019) The nature of Ni-O pairs for ethane activation on $\mathrm{NiO}(100)$ and $\mathrm{NiO}(110)$ surfaces. Mol Catal 474:110417
33. Skoufa Z, Xantri G, Heracleous E et al (2014) A study of Ni-Al-O mixed oxides as catalysts for the oxidative conversion of ethane to ethylene. Appl Catal A Gen 471:107-117

34. Smoláková L, Čapek L, Botková Š et al (2011) Activity of the $\mathrm{Ni}-\mathrm{Al}$ mixed oxides prepared from hydrotalcite-like precursors in the oxidative dehydrogenation of ethane and propane. Top Catal 54(16-18):1151-1162

35. Govind Rajan A, Martirez JMP, Carter EA (2020) Facet-independent oxygen evolution activity of pure $\beta-\mathrm{NiOOH}$ : different chemistries leading to similar overpotentials. J Am Chem Soc 142(7):3600-3612

36. Xue Z, Zhang XY, Qin JQ et al (2019) Revealing Ni-based layered double hydroxides as high-efficiency electrocatalysts for the oxygen evolution reaction: a DFT study. J Mater Chem A 7(40):23091-23097

37. Song F, Busch MM, Lassalle-Kaiser B et al (2019) An unconventional iron nickel catalyst for the oxygen evolution reaction. ACS Cent Sci 5(3):558-568

38. Martirez JMP, Carter EA (2019) Unraveling oxygen evolution on iron-doped $\beta$-nickel oxyhydroxide: the key role of highly active molecular-like sites. J Am Chem Soc 141(1):693-705

39. Horànyi TS (1989) Investigation of the effects of heat treatment on the $\beta-\mathrm{Ni}(\mathrm{OH})_{2}-\beta-\mathrm{NiOOH}$ system using IR spectroscopy. Thermochim Acta 142(1):143-150

40. Horányi TS (1989) The thermal stability of the $\beta-\mathrm{Ni}(\mathrm{OH})_{2}-\beta$ $\mathrm{NiOOH}$ system. Thermochim Acta 137(2):247-253

41. Solsona B, López Nieto JM, Concepción P et al (2011) Oxidative dehydrogenation of ethane over $\mathrm{Ni}-\mathrm{W}-\mathrm{O}$ mixed metal oxide catalysts. J Catal 280(1):28-39

42. Kresse G, Furthmüller J (1996) Efficiency of ab initio total energy calculations for metals and semiconductors using a plane-wave basis set. Comput Mater Sci 6(1):15-50

43. Blöchl PE (1994) Projector augmented-wave method. Phys Rev B 50(24):17953-17979

44. Dudarev SL, Botton GA, Savrasov SY et al (1998) Electronenergy-loss spectra and the structural stability of nickel oxide: an LSDA + U study. Phys Rev B 57(3):1505

45. Grimme S, Antony J, Ehrlich S et al (2010) A consistent and accurate ab initio parametrization of density functional dispersion correction (DFT-D) for the 94 elements H-Pu. J Chem Phys 132(15): 154104

46. Casas-Cabanas M, Radin MD, Kim J et al (2018) The nickel battery positive electrode revisited: stability and structure of the $\beta$-NiOOH phase. J Mater Chem A 6(39):19256-19265

47. Li YF, Selloni A (2014) Mosaic texture and double c-axis periodicity of $\beta-\mathrm{NiOOH}$ : insights from first-principles and genetic algorithm calculations. J Phys Chem Lett 5(22):3981-3985

48. Tkalych AJ, Yu K, Carter EA (2015) Structural and electronic features of $\beta-\mathrm{Ni}(\mathrm{OH})_{2}$ and $\beta-\mathrm{NiOOH}$ from first principles. J Phys Chem C 119(43):24315-24322

49. Trotochaud L, Young SL, Ranney JK et al (2014) Nickel-iron oxyhydroxide oxygen-evolution electrocatalysts: the role of intentional and incidental iron incorporation. J Am Chem Soc 136(18):6744-6753

50. Henkelman G, Jónsson H (1999) A dimer method for finding saddle points on high dimensional potential surfaces using only first derivatives. J Chem Phys 111(15):7010-7022

51. Henkelman G, Uberuaga BP, Jónsson H (2000) A climbing image nudged elastic band method for finding saddle points and minimum energy paths. J Chem Phys 113(22):9901-9904

52. Braga AAC, Maseras F, Urbano J et al (2006) Mechanism of alkane $\mathrm{C}-\mathrm{H}$ bond activation by copper and silver homoscorpionate complexes. Organometallics 25(22):5292-5300

53. Chen KD, Iglesia E, Bell AT (2001) Isotopic tracer studies of reaction pathways for propane oxidative dehydrogenation on molybdenum oxide catalysts. J Phys Chem B 105(3):646-653 
54. Deshlahra P, Carr RT, Chai SH et al (2015) Mechanistic details and reactivity descriptors in oxidation and acid catalysis of methanol. ACS Catal 5(2):666-682

55. Cao L, Dai PC, Zhu L et al (2020) Graphitic carbon nitride catalyzes selective oxidative dehydrogenation of propane. Appl Catal B Environ 262:118277

56. Rozanska X, Fortrie R, Sauer J (2007) Oxidative dehydrogenation of propane by monomeric vanadium oxide sites on silica support. J Phys Chem C 111(16):6041-6050

57. Cheng L, Ferguson GA, Zygmunt SA et al (2013) Structureactivity relationships for propane oxidative dehydrogenation by anatase-supported vanadium oxide monomers and dimers. J Catal 302:31-36

58. Skoufa Z, Heracleous E, Lemonidou AA (2015) On ethane ODH mechanism and nature of active sites over NiO-based catalysts via isotopic labeling and methanol sorption studies. J Catal 322:118-129

59. Fung V, Tao FF, Jiang DE (2016) Understanding oxidative dehydrogenation of ethane on $\mathrm{Co}_{3} \mathrm{O}_{4}$ nanorods from density functional theory. Catal Sci Technol 6(18):6861-6869

60. Grillo F, Natile MM, Glisenti A (2004) Low temperature oxidation of carbon monoxide: the influence of water and oxygen on the reactivity of $\mathrm{a} \mathrm{Co}_{3} \mathrm{O}_{4}$ powder surface. Appl Catal B Environ 48(4):267-274

61. Evans MG, Polanyi M (1938) Inertia and driving force of chemical reactions. Trans Faraday Soc. https://doi.org/10.1039/tf93834000 11

62. Bronsted JN (1928) Acid and basic catalysis. Chem Rev 5(3):231-338

63. Deshlahra P, Iglesia E (2016) Reactivity and selectivity descriptors for the activation of $\mathrm{C}-\mathrm{H}$ bonds in hydrocarbons and oxygenates on metal oxides. J Phys Chem C 120(30):16741-16760

64. Liu YL, Annamalai L, Deshlahra P (2019) Effects of lattice O atom coordination and pore confinement on selectivity limitations for ethane oxidative dehydrogenation catalyzed by vanadium-oxo species. J Phys Chem C 123(46):28168-28191

65. Annamalai L, Liu YL, Deshlahra P (2019) Selective C-H bond activation via NOx-mediated generation of strong $\mathrm{H}$-abstractors. ACS Catal 9(11):10324-10338
66. Niu SQ, Sun YC, Sun GJ et al (2019) Stepwise electrochemical construction of $\mathrm{FeOOH} / \mathrm{Ni}(\mathrm{OH})_{2}$ on $\mathrm{Ni}$ foam for enhanced electrocatalytic oxygen evolution. ACS Appl Energy Mater 2(5):3927-3935

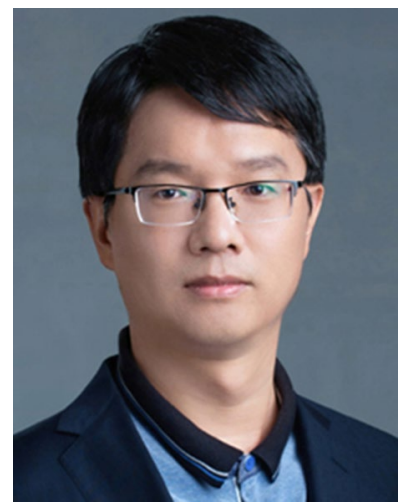

Dr. Xinli Zhu is a professor at the School of Chemical Engineering and Technology, Tianjin University. $\mathrm{He}$ received his $\mathrm{BS}$ in Chemical Engineering in 2002 and Ph.D. in 2007 from Tianjin University. He was a postdoctoral research fellow at the University of Oklahoma in 2007 2011. He joined Tianjin University in 2011. His research interest includes the catalytic conversion of biomass-derived oxygenates to chemicals and fuels by using combined experiapproaches. mental and theoretical

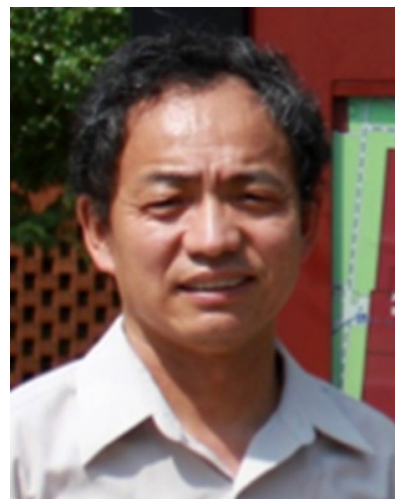

Dr. Qingfeng Ge is a Distinguished Scholar and Professor in the Department of Chemistry and Biochemistry of Southern Illinois University Carbondale and Associate Editor of Journal of $\mathrm{CO}_{2}$ Utilization. Dr. Ge received his education from Tianjin University, China, worked as Research Associate in Copenhagen University, Denmark, and Cambridge University, UK, and was Research Scientist in University of Virginia before joining SIUC in 2003. 